\title{
Extragenital Gonorrhoea in Men Who Have Sex with Men: A Retrospective Study in a STI Clinic in Lisbon, Portugal
}

\author{
Gonorreia Extragenital em Homens Que Têm Sexo com \\ Homens: Estudo Retrospetivo numa Consulta de IST em \\ Lisboa, Portugal
}

\author{
Margarida Moura VALEJO COELHO $\otimes^{1}$, Eugénia MATOS-PIRES ${ }^{1}$, Vasco SERRÃO ${ }^{1}$, Ana RODRIGUES ${ }^{1}$, \\ Cândida FERNANDES 1 \\ Acta Med Port 2018 May;31(5):247-253 - https://doi.org/10.20344/amp.10146
}

\section{ABSTRACT}

Introduction: Recent studies worldwide reveal a significant prevalence of extragenital infections by Neisseria gonorrhoeae among men who have sex with men. We aimed to analyse the frequency and characteristics of extragenital gonococcal infections diagnosed in men who have sex with men in a walk-in Sexually Transmitted Infection clinic in Lisbon, Portugal.

Material and Methods: We conducted a cross-sectional, retrospective study of the anorectal and/or oropharyngeal Neisseria gonorrhoeae infections in men who have sex with men, diagnosed in our Sexually Transmitted Infection clinic between January 2014 and December 2016.

Results: We found extragenital infection in 87 cases of gonorrhoea identified in men who have sex with men in this period, including: 49 cases of anorectal disease, 9 of oropharyngeal disease, 13 cases of infection at both extragenital sites, and 16 of simultaneous extragenital and urogenital gonorrhoea. Patients' ages ranged from 17 to 64 years (median: 28 years). Forty-seven (54\%) of the patients did not present with any extragenital symptoms. Thirty $(35 \%)$ were human immunodeficiency virus-1-positive.

Discussion: Since most extragenital Neisseria gonorrhoeae infections are asymptomatic, they may be missed and go untreated unless actively investigated. Current international guidelines recommend the screening of gonorrhoea at extragenital sites in men who have sex with men because anorectal and oropharyngeal infections constitute a potential disease reservoir, and may facilitate transmission and/or acquisition of human immunodeficiency virus infection.

Conclusion: Our results highlight the relevance of testing men who have sex with men for Neisseria gonorrhoeae at extragenital sites, regardless of the existence of local complaints. The implementation of adequate screening programmes in Portugal should be considered. We also reinforce the need to raise awareness in the population regarding the adoption of prophylactic measures against transmission of sexually transmitted infections during anal and/or oral sexual exposure.

Keywords: Gonorrhea; Homosexuality, Male; Neisseria gonorrhoeae; Portugal

\section{RESUMO}

Introdução: Estudos internacionais recentes revelam uma prevalência significativa de infeções extragenitais por Neisseria gonorrhoeae em homens que têm sexo com homens. Pretendemos analisar a frequência e caraterísticas das infeções gonocócicas extragenitais diagnosticadas em homens que têm sexo com homens numa consulta aberta de Infeções Sexualmente Transmissíveis em Lisboa, Portugal.

Material e Métodos: Conduzimos um estudo observacional transversal, retrospetivo, das infeções anorrectais e/ou orofaríngeas por Neisseria gonorrhoeae em homens que têm sexo com homens, diagnosticadas na nossa consulta de Infeções Sexualmente Transmissíveis entre janeiro de 2014 e dezembro de 2016.

Resultados: Detetámos infeção extragenital em 87 dos casos de gonorreia identificados em homens que têm sexo com homens no período analisado, incluindo: 49 casos de doença anorrectal, 9 de doença orofaríngea, 13 casos de infeção em ambas as localizações extragenitais, e 16 de gonorreia simultaneamente extragenital e urogenital. A idade dos doentes variou entre 17 e 64 anos (mediana: 28 anos). Quarenta e sete (54\%) dos doentes não apresentavam qualquer sintoma extragenital. Trinta (35\%) tinham também infeção pelo vírus da imunodeficiência humana-1.

Discussão: Dado que a maioria das infeções extragenitais por Neisseria gonorrhoeae são assintomáticas, estas podem não ser diagnosticadas, e não tratadas, se não pesquisadas ativamente. Em várias normas de orientação clínica internacionais atuais é recomendado o rastreio da gonorreia em localizações extragenitais em homens que têm sexo com homens, visto que as infeções anorrectais e orofaríngeas constituem potenciais reservatórios da doença e podem facilitar a transmissão e/ou aquisição de infeção pelo vírus da imunodeficiência humana.

Conclusão: Os nossos resultados apontam para a relevância de testar os homens que têm sexo com homens para a presença de Neisseria gonorrhoeae em localizações extragenitais, independentemente da existência de sintomas locais. A implementação de programas de rastreio adequados em Portugal deverá ser considerada. Relevamos também a necessidade de sensibilizar a população para a adoção de medidas profiláticas contra a transmissão de infeções sexualmente transmissíveis durante o contacto sexual anal e/ou oral.

Palavras-chave: Gonorreia; Homossexualidade Masculina; Neisseria gonorrhoeae; Portugal

\footnotetext{
1. Department of Dermatology and Venereology. Centro Hospitalar de Lisboa Central. Lisbon. Portugal.

$\bowtie$ Autor correspondente: Margarida Moura Valejo Coelho. margarida.m.v.coelho@chlc.min-saude.pt

Recebido: 28 de dezembro de 2017 - Aceite: 03 de abril de 2018 | Copyright @ Ordem dos Médicos 2018
} 


\section{INTRODUCTION}

Gonorrhoea is a common, notifiable sexually transmitted infection (STI) caused by Neisseria gonorrhoeae. ${ }^{1,2}$ Transmission is made by direct inoculation of an infected mucosal secretion, and can occur through genital-genital, genital-anorectal, oro-genital and oro-anal contact. ${ }^{2}$ Recent studies worldwide have revealed a significant prevalence of extragenital $N$. gonorrhoeae infections, particularly among men who have sex with men (MSM) (in previous studies: $2 \%-9.6 \%$ for anorectal gonorrhoea, $2 \%-8 \%$ for oropharyngeal gonorrhoea). ${ }^{3-15}$ As gonococcal infections at the anorectal and oropharyngeal sites are frequently asymptomatic, ${ }^{2,9,10,15}$ and often occur without concurrent urogenital infection, ${ }^{7,16}$ they may be undiagnosed, increasing the risk of complications and constituting potential disease reservoirs. ${ }^{17,18}$ These infections are also thought to facilitate transmission and/or acquisition of human immunodeficiency virus (HIV) infection. ${ }^{10,19-21}$ To address this public health concern, the need for screening and testing for $N$. gonorrhoeae at extragenital sites has been emphasised in recent years, ${ }^{19}$ and several guidelines have been made accordingly. 2,10,22-27 In Portugal, there are currently no standardised national guidelines on this subject, making the screening non-uniform among different medical institutions.

With this study we aimed to analyse the frequency, anatomical location and clinical presentation of extragenital gonococcal infections diagnosed in MSM in a walk-in STI clinic in Lisbon, Portugal, over three years.

\section{MATERIAL AND METHODS}

We conducted a cross-sectional, retrospective study in the walk-in STI clinic of the Department of Dermatology and Venereology of Centro Hospitalar de Lisboa Central, a tertiary hospital in Lisbon, Portugal.

According to the practice at our walk-in STI clinic, after a thorough medical history and physical examination, all the MSM individuals that consent are routinely screened for urogenital, anorectal and oropharyngeal gonorrhoea, regardless of the existence of local complaints. Oropharyngeal specimens are collected with swabs by the medical staff, whereas anorectal swabs are patientcollected during the office visit, upon proper instruction. The specimens are all analysed at the Microbiology Laboratory of our institution. Since nucleic acid amplification tests (NAATs) are considered the test of choice for screening for rectal and pharyngeal gonococcal infections, ${ }^{2,22}$ a commercial NAAT (AmpliSens ${ }^{\circledR} N$. gonorrhoeae / C. trachomatis / M. genitalium / T. vaginalis MULTIPRIMEFTR PCR kit, AmpliSens, Moscow, Russia) is used, which, if positive, confirms infection. Other STIs are also routinely screened, including Chlamydia trachomatis infections, syphilis, HIV and hepatitis C.

We reviewed all the 157 cases of gonorrhoea diagnosed in our clinic among the 1798 male patients reporting to be MSM, between January 1, 2014 and December 31, 2016, and included in this study only the cases of laboratoryconfirmed anorectal and/or oropharyngeal gonorrhoea
( $n=87$ ), with or without concurrent urogenital gonococcal infection, which constituted our convenience sample.

We collected information on these patients' sociodemographic data, medical history, sexual practices and laboratory results by reviewing their clinical records, excluding any personal identifiers, in accordance with institutional, national and international ethical standards. Assessed variables included the patient's age, nationality and sexual orientation, previous history of STIs (including known HIV infection), number of sexual partners in the preceding 6 months, condom use, date of extragenital gonorrhoea diagnosis, site(s) of gonococcal infection, symptoms and consultation motives, and concurrent STIs at the time of gonorrhoea diagnosis (including de novo HIV diagnosis). In some cases, not all the intended information was available in the medical files.

We performed a descriptive statistical analysis of sociodemographic, clinical and laboratorial data, that we summarised by frequency and percent distributions, measures of central tendency and a measure of dispersion, using the software Microsoft Excel 2016 (Microsoft Office 365 ProPlus).

\section{RESULTS}

\section{Characteristics of the study population}

We identified 87 cases of extragenital gonococcal infection in MSM in this 3-year period, representing 55\% of the cases of gonorrhoea in MSM patients: 18 cases were diagnosed during the year 2014, 27 in 2015, and 42 in 2016. These diagnoses corresponded to 79 patients, as 6 patients had more than one infection during the considered time period ( 4 patients had 2 episodes of infection, and 2 patients had 3 ), with the interval between such multiple episodes ranging from 8 to 33 months. The prevalence of extragenital gonorrhoea in the MSM population of our clinic was, therefore, approximately $4 \%$.

Patients' ages at the time of diagnosis showed an asymmetric distribution, ranging from a minimum of 17 to a maximum of 64 years (median age 28 years; arithmetic mean 31.3; trimmed mean 30.7; standard deviation 9.8): in $1(1 \%)$ case the patient was younger than 18 years of age, $28(32 \%)$ were $18-25$ years old, $44(51 \%)$ were in the 26 - 40 years age group, and $14(16 \%)$ were $41-64$ years old.

The patients were Portuguese in the great majority of the cases $(70 ; 81 \%)$. Other countries of origin were, in order of decreasing frequency, Brazil (7), Italy (3), Spain (2), United Kingdom (1), Belgium (1), Greece (1), Romania (1) and Cape Verde (1).

\section{Characteristics of extragenital gonococcal infections and presence of local symptoms}

The frequency of gonococcal infections by anatomical location is shown in Fig. 1. Our sample comprised 49 $(57 \%)$ cases of exclusively anorectal gonorrhoea, $9(10 \%)$ of oropharyngeal disease, $13(15 \%)$ cases of infection 
Sites of gonococcal infection

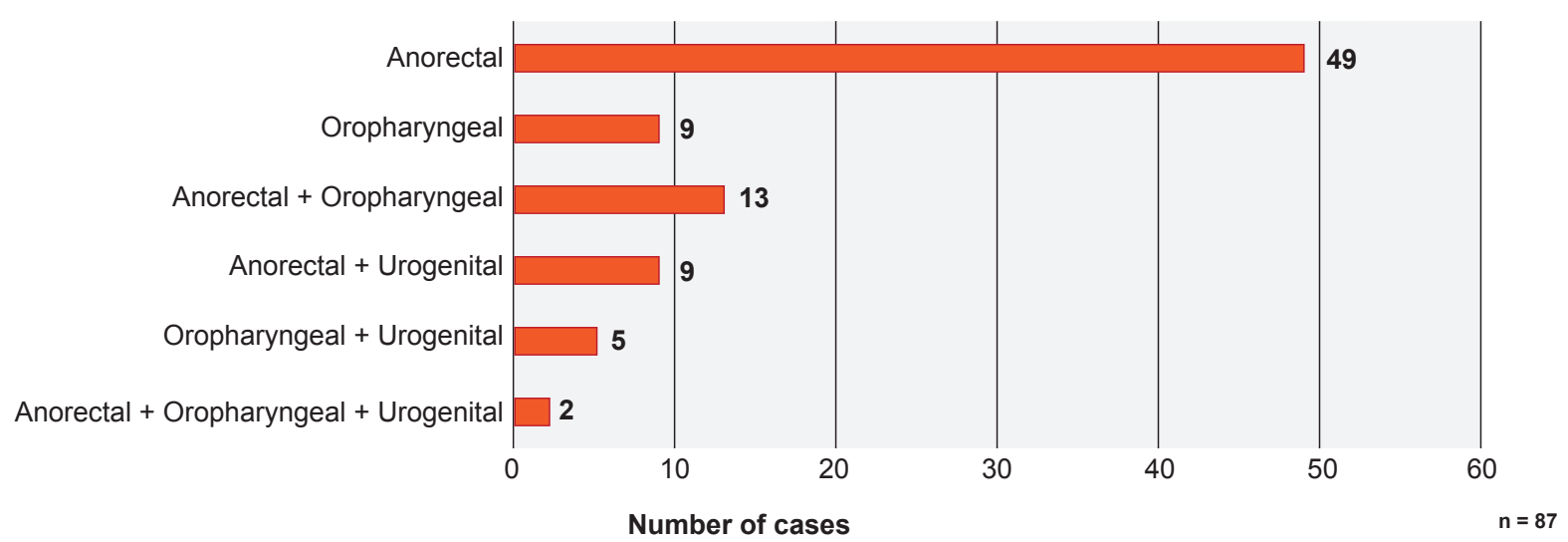

Figure 1 - Anatomical location of extragenital gonorrhoea. Distribution of gonococcal infections by site(s) $(n=87)$ : exclusively extragenital infections accounted for the majority of cases (71), whereas the remainder 16 cases corresponded to mixed extragenital and urogenital infections.

at both these extragenital sites, and $16(18 \%)$ cases of simultaneous extragenital and urogenital gonococcal infection; the latter included 9 cases of mixed anorectal and urogenital gonorrhoea, 5 of oropharyngeal and urogenital infection, and 2 cases of anorectal, oropharyngeal and urogenital disease. Therefore, exclusively extragenital infections accounted for the majority of cases $(71 ; 82 \%)$, whereas the remainder $16(18 \%)$ corresponded to mixed extragenital and urogenital infections. Altogether there was anorectal infection in 73 of the cases, and oropharyngeal in 29.

Patients reported any symptoms in 61 cases (70\%) - (Fig. 2A); general STI screening and fear of disease, particularly after unsafe sex, were the other most frequent consultation motives. Anorectal complaints included perianal erythema, anal itching or burning sensation, anorectal pain, anorectal discharge, anorectal haemorrhage, (peri)anal erosions, diarrhoea, painful defecation, tenesmus or sensation of rectal fullness. Mentioned oropharyngeal symptoms were sore throat and odynophagia. However, in only 40 (46\%) cases did the patients have anorectal and/or oropharyngeal clinical complaints (Figs. 2A and 2B), including proctitis symptoms in 34 cases, oropharyngeal symptoms in 2 , both anorectal and oropharyngeal complaints in 1 case, symptoms suggesting proctitis and urethritis in 2 , and pharyngitis and urethritis in 1 case (Fig. 2B). In most cases of extragenital gonorrhoea $(47 ; 54 \%)$ the patients did not present with any localising symptoms (Figs. 2A and 2B): 26 $(30 \%)$ infections were completely asymptomatic, whereas in the 21 remainder cases (24\%) patients reported urethral symptoms (13 cases), and other miscellaneous complaints, including condylomatous lesions, genital erosions or ulcers, nonspecific balanoposthitis, and eczema. Altogether we found local complaints possibly associated with gonococcal infection at these extragenital sites only in $38(52 \%)$ of the anorectal and in $4(14 \%)$ of the oropharyngeal confirmed infections (Figs. 3A and 3B).

\section{Other STIs}

Thirty patients (35\%) were HIV-1-infected at the time of extragenital gonorrhea diagnosis: HIV infection was previously known in 26 cases, but in 4 cases it was newly diagnosed during routine STI screening. One patient had previously been diagnosed with hepatitis $\mathrm{C}$ infection.

In $19(22 \%)$ cases, concurrent syphilis infection (mostly recent) was found. Infection by $C$. trachomatis was present

\section{A Clinical presentation}

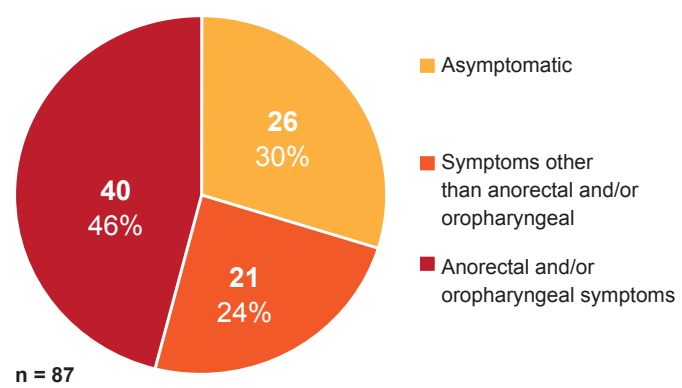

\section{B Groups of symptoms}

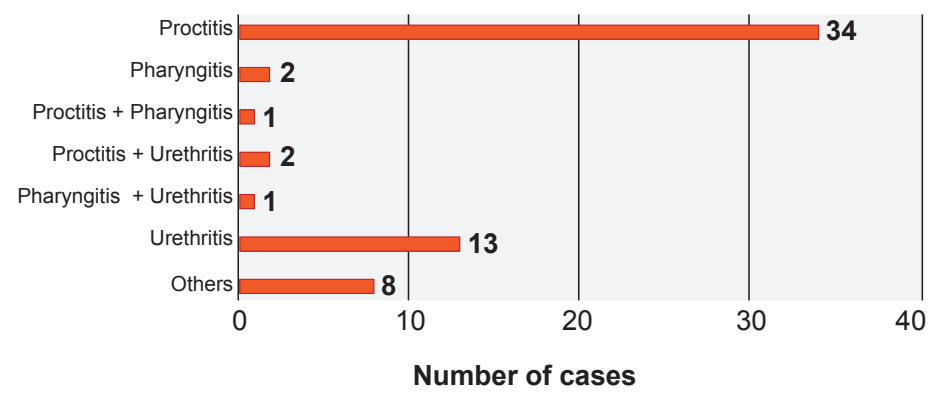

Figure 2 - Clinical presentation of extragenital gonorrhoea. (A) In most cases of extragenital gonococcal infection (47; $54 \%$ ) the patients did not present with any anorectal and/or oropharyngeal localising symptoms, including $26(30 \%)$ cases in which infections were completely asymptomatic. (B) Distribution of the 61 symptomatic cases by groups of symptoms. 


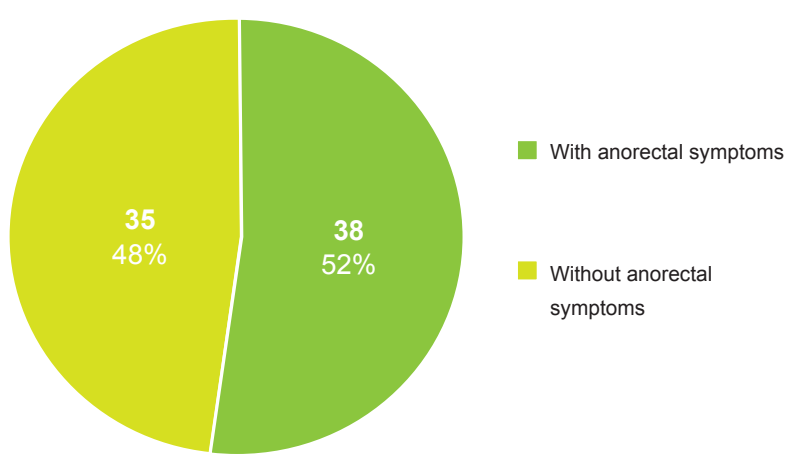

B Oropharyngeal infections

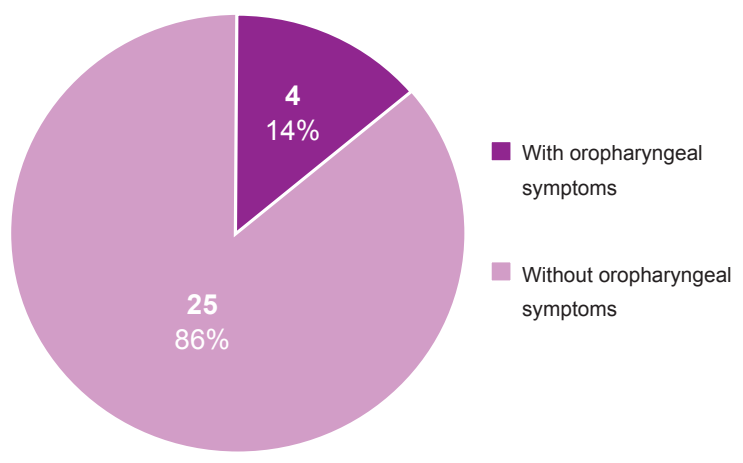

Figure 3 - Local symptoms in extragenital gonorrhoea. (A) Distribution of the 73 anorectal gonococcal infections by the presence or absence of local symptoms. (B) Distribution of the 29 oropharyngeal gonococcal infections by the presence or absence of local symptoms.

at the same time in $14(16 \%)$ cases, including 12 anorectal, 1 oropharyngeal, and 1 urogenital infections. Mycoplasma genitalium was simultaneously found in $5(6 \%)$ cases, including 2 anorectal, 1 oropharyngeal, and 2 urogenital infections.

Concurrent (peri)anal disease caused by human papillomavirus (HPV) was identified in $6(7 \%)$ cases. Anogenital herpes simplex virus type 2 (HSV-2) infection was diagnosed concurrently in $2(2 \%)$ cases.

Finally, reviewing the patients' past medical history, previous episodes of STIs were found in 34 (39\%) cases, including 15 gonococcal infections, 9 of which affecting extragenital sites.

\section{Risk factors and behaviours}

Information on the number of sexual partners in the preceding six months was provided by patients and registered in the medical files in 77 cases. The results available for this retrospective analysis were grouped in categories as follows: ' 1 sexual partner' in 12 cases $(16 \%$ of the answers), ' 2 - 3 partners' in 24 cases (31\%), ' 4 9 partners' in 24 cases (31\%), '10 or more partners' in 17 cases $(22 \%)$.

Information on the habits of condom use was provided by patients and registered in the medical files only in 39 cases (approximately $45 \%$ of the study sample). These results were, therefore, not included in this analysis.

\section{DISCUSSION}

To the best of our knowledge, this is the first Portuguese study to investigate anorectal and oropharyngeal infections by $N$. gonorrhoeae among MSM. We identified a considerable number of cases of extragenital gonorrhoea in this population in our STI clinic, showing a worrisome increasing tendency over the three years studied (annual increase: approximately 1.5 times). Anorectal infection was found considerably more frequently than oropharyngeal infection. Moreover, six patients had more than one episode of extragenital gonorrhoea diagnosed in this period of time, constituting cases of reinfection.

Most extragenital gonococcal infections occurred in young adults, as the age group of ' $26-40$ years' accounted for most cases, followed by the ' $18-25$ years' group.

Considering the patients' countries of origin, although most cases corresponded to Portuguese MSM, our sample included also several foreigners, living in or visiting Lisbon. This is also a noteworthy finding, reminding that population movements (migration, travelling, etc.) may influence the dynamics of infectious diseases, particularly STIs, and pose challenges to prevention and control efforts, particularly in major urban areas. Walk-in STI clinics like ours are very useful to facilitate people's access to healthcare, including STI testing and treatment, with no appointment required.

Exclusive extragenital gonorrhoea without concurrent urogenital infection accounted for the majority of cases. This means that we identified a considerable number of gonococcal infections that would have been undiagnosed if urethral screening alone had been performed. Furthermore, in most cases (54\%) the patients did not present with any extragenital symptoms, including $26(30 \%)$ cases of completely asymptomatic infection. Considering that we found local complaints possibly associated with gonococcal infection at extragenital sites only in $52 \%$ of the anorectal and in $14 \%$ of the oropharyngeal infections, $48 \%$ of the anorectal and $86 \%$ of the oropharyngeal infections would have been missed if only the patients reporting local symptoms had been tested for $N$. gonorrhoeae at these sites. In fact, it is known that anorectal and oropharyngeal gonococcal infections are usually asymptomatic., ${ }^{2,7,9,20}$ According to other authors, anorectal symptoms, like itching, burning, pain, discharge and haemorrhage, are less common but more specific for infection, whereas oropharyngeal complaints, like sore throat, are more commonly reported but nonspecific. ${ }^{7}$ Therefore, extragenital gonorrhoea may be missed unless it is actively investigated..$^{19}$ Undiagnosed and untreated anorectal and oropharyngeal infections can lead to complications and constitute potential disease reservoirs, ${ }^{17}$ which may contribute to the increasing transmission, incidence and antimicrobial resistance of gonorrhoea; ${ }^{18}$ the possible role of oropharyngeal infections in promoting resistance among Neisseria species is of particular concern. ${ }^{28,29}$ Our results confirm the relevance 
of testing for gonorrhoea at extragenital sites in MSM, regardless of local complaints.

Reducing the duration of anorectal and/or oropharyngeal symptomatic and subclinical infections, by timely diagnosis and treatment, is an important strategy to reduce gonorrhoea prevalence. To address this public health concern, several current international guidelines recommend testing for $N$. gonorrhoeae infection at extragenital sites, although different strategies have been proposed worldwide: the Centers for Disease Control and Prevention (CDC), ${ }^{22}$ the International Union against Sexually Transmitted Infections (IUSTI), ${ }^{2}$ the Canadian guidelines, ${ }^{25}$ and the British guidelines ${ }^{24}$ generally recommend screening for anorectal and/or oropharyngeal gonorrhoea in MSM accordingly to the reported history of anal and/or oral sexual exposure (with more frequent screening of MSM with risk behaviours for STIs), whereas the Australian STI in Gay Men Action (STIGMA) group ${ }^{26}$ and the Norwegian guidelines ${ }^{27}$ recommend annual screening for MSM (every 3- 6 months for high-risk MSM) at all sites, regardless of reported location of sexual contact. In our perspective, and in accordance to previous work, ${ }^{30}$ patients' reported sexual activities do not always match their actual practices, limiting the accuracy of history-based screening. Considering this, we currently perform and recommend routine screening of all MSM for gonorrhoea at the urogenital tract and extragenital sites, at least annually (every 3-6 months for high-risk MSM). We use NAATs because they are considered the test of choice for screening for rectal and pharyngeal gonococcal infections, ${ }^{2,22}$ due to their high sensibility $(>96 \%)$ in symptomatic and asymptomatic infections, high specificity, ${ }^{2,22}$ and the possibility of obtaining specimens using patient-collected swabs. ${ }^{19}$ In Portugal, there is a commendable national system for epidemiological surveillance (Sistema Nacional de Vigilância Epidemiológica - SINAVE), to which new cases of gonorrhoea are reported via an online platform. However, in our country, as in others, ${ }^{31} N$. gonorrhoeae testing at extragenital sites is performed almost exclusively at STI clinics, and thus many diagnoses and treatment opportunities may be missed in other medical settings. Also, unfortunately, there are currently no national guidelines specifically recommending extragenital STI testing, which compromises routine, standardised screening in most institutions. Implementation of appropriate screening programmes may find several constraints in Portugal, including limited institutional funding and material availability, short appointment times for medical visits, insufficient training of physicians in addressing STIs, and patients' lack of risk awareness and/or fear of judgement. Finally, more cost-effectiveness studies on this subject would be of value.

Insufficient condom use has been reported in other studies, and, although gonorrhoea transmission is more likely during genito-anal contact, oro-genital sex is more frequently practised between casual partners and more often without condom. ${ }^{7,17}$ Interestingly, a mathematical model has even shown that oral and anal sex are key to sustaining gonorrhoea at endemic levels in MSM populations, and that increasing the use of condoms during such practices could reduce or virtually eliminate this infection among MSM. ${ }^{17}$ Also, we found that in most cases patients reported having had two or more sexual partners in the six months preceding the extragenital gonorrhoea diagnosis. Considering this, we reinforce the need to sensitise the population towards the importance of adopting prophylactic measures against the transmission of gonorrhoea and other STIs, namely the consistent use of condom, during anal and/or oral sexual exposure.

Finally, as seen in previous studies, ${ }^{10}$ the association of extragenital gonorrhoea with other STIs was also common. This included extragenital $C$. trachomatis and M. genitalium concurrent infections in 13 and 3 cases, respectively. More importantly, patients were HIV-1-positive at the time of extragenital gonorrhoea diagnosis in 30 (35\%) cases, including 4 de novo HIV diagnoses established during routine screening. Whereas HIV status is an independent risk factor for oropharyngeal and anorectal infections, ${ }^{7,20}$ gonococcal infection at extragenital sites is also thought to facilitate transmission and/or acquisition of HIV. ${ }^{10,19,20}$ This is due not only to shared risk behavioural factors for both STIs, including insufficient condom use and multiple sexual partners, but also to biological susceptibility related to inflammation and immunosuppression. Therefore, STI screening should routinely include HIV testing, and regular STI screening, including testing for $N$. gonorrhoeae at extragenital sites, regardless of symptoms, is recommendable in HIV-positive MSM. ${ }^{22,32}$

Our analysis was, however, restricted by some limitations that must be considered when interpreting results. First, we studied a small, convenience sample, which included only MSM who visited our walk-in STI clinic in Lisbon during a 3-year time frame. This prevents extrapolation of our results to the total MSM population in Portugal, as we did not recruit a representative sample and conducted a singlecentre study, in a high-risk setting. Also, some of the MSM who visited our clinic during the considered time period may have declined anorectal and/or oropharyngeal swabbing, possibly limiting the detection of some infections.

Second, as we conducted a retrospective analysis based on the collection of clinical information registered in the patients' records, there were data missing regarding some variables, namely the number of sexual partners and condom use habits, allowing only a limited interpretation of these results.

\section{CONCLUSION}

In this study, we found a considerable burden and an increasing frequency of extragenital gonorrhoea (particularly anorectal infections) among MSM, in the STI clinic of a tertiary referral hospital in Lisbon, Portugal, in recent years. Exclusively extragenital infections without concurrent urogenital gonorrhoea accounted for the majority of cases, and most anorectal and/or oropharyngeal gonococcal infections were asymptomatic. Our findings reinforce 
the relevance of screening MSM for $N$. gonorrhoeae at extragenital sites, regardless of the existence of local complaints, in order to prevent these potential infection reservoirs from being underdiagnosed and untreated. Screening is of particular importance in HIV-positive MSM, and in those having multiple sexual partners and unprotected anal and/or oral sex. This study might inform future guidelines and standardised procedures concerning the screening of anorectal and oropharyngeal gonorrhoea among MSM in Portugal.

\section{OBSERVATIONS}

The results have been partially presented orally in two conferences: XVI Congresso Nacional de Dermatologia e Venereologia (Lisbon, Portugal, December 1-3, 2016); 26th Congress of the European Academy of Dermatology and Venereology (Geneva, Switzerland, September 13-17, 2017).

\section{REFERENCES}

1. Newman L, Rowley J, Vander Hoorn S, Wijesooriya NS, Unemo M, Low N, et al. Global Estimates of the Prevalence and Incidence of Four Curable Sexually Transmitted Infections in 2012 Based on Systematic Review and Global Reporting. PLoS One. 2015;10:e0143304.

2. Bignell C, Unemo M on behalf of the European STI Guidelines Editorial Board. 2012 European guideline on the diagnosis and treatment of gonorrhoea in adults. Int J STD AIDS. 2013;24:85-92.

3. Kent CK, Chaw JK, Wong W, Liska S, Gibson S, Hubbard G, et al. Prevalence of rectal, urethral, and pharyngeal chlamydia and gonorrhea detected in 2 clinical settings among men who have sex with men: San Francisco, California, 2003. Clin Infect Dis. 2005;41:67-74.

4. Bissessor M, Tabrizi SN, Fairley CK, Danielewski J, Whitton B, Bird S, et al. Differing Neisseria gonorrhoeae bacterial loads in the pharynx and rectum in men who have sex with men: Implications for gonococcal detection, transmission, and control. J Clin Microbiol. 2011;49:4304-6.

5. Vodstrcil LA, Fairley CK, Fehler G, Leslie D, Walker J, Bradshaw CS, et al. Trends in chlamydia and gonorrhea positivity among heterosexual men and men who have sex with men attending a large urban sexual health service in Australia, 2002-2009. BMC Infect Dis. 2011;11:158.

6. Reinton N, Moi H, Olsen AO, Zarabyan N, Bjerner J, Tønseth TM, et al. Anatomic distribution of Neisseria gonorrhoeae, Chlamydia trachomatis and Mycoplasma genitalium infections in men who have sex with men. Sex Health. 2013;10:199-203.

7. Dudareva-Vizule S, Haar K, Sailer A, Wisplinghoff $H$, Wisplinghoff $F$, Marcus $U$, et al. Prevalence of pharyngeal and rectal Chlamydia trachomatis and Neisseria gonorrhoeae infections among men who have sex with men in Germany. Sex Transm Infect. 2014;90:46-51.

8. Allan-Blitz LT, Leon SR, Bristow CC, Konda KA, Vargas SK, Flores JA, et al. High prevalence of extra-genital chlamydial or gonococcal infections among men who have sex with men and transgender women in Lima, Peru. Int J STD AIDS. 2017;28:138-44.

9. Tongtoyai J, Todd CS, Chonwattana W, Pattanasin S, Chaikummao S, Varangrat A, et al. Prevalence and correlates of Chlamydia trachomatis and Neisseria gonorrhoeae by anatomic site among urban Thai men who have sex with men. Sex Transm Dis. 2015;42:440-9.

10. Chan PA, Robinette A, Montgomery M, Almonte A, Cu-Uvin S, Lonks $\mathrm{JR}$, et al. Extragenital infections caused by Chlamydia trachomatis and Neisseria gonorrhoeae: a review of the literature. Infect Dis Obstet Gynecol. 2016;2016:5758387.

11. Peters RP, Verweij SP, Nijsten N, Ouburg S, Mutsaers J, Jansen CL, et al. Evaluation of sexual history-based screening of anatomic sites for chlamydia trachomatis and neisseria gonorrhoeae infection in men having sex with men in routine practice. BMC Infect Dis. 2011;11:203.

12. Benn PD, Rooney G, Carder C, Brown M, Stevenson SR, Copas A, et al. Chlamydia trachomatis and Neisseria gonorrhoeae infection and the sexual behaviour of men who have sex with men. Sex Transm Infect. 2007;83:106-12.

13. Centers for Disease Control and Prevention (CDC). Clinic-based

\section{DATA CONFIDENTIALITY}

The authors declare having followed the protocols in use at their working center regarding patients' data publication. Patient consent obtained.

\section{PROTECTION OF HUMANS AND ANIMALS}

The authors declare that the research procedures were performed according to the regulations of the institution's ethics committee and the Code of Ethics of the World Medical Association (Declaration of Helsinki).

\section{CONFLICTS OF INTEREST}

The authors declare that there is no conflict of interest.

\section{FUNDING SOURCES}

No funding was received to conduct this study.

testing for rectal and pharyngeal Neisseria gonorrhoeae and Chlamydia trachomatis infections by community-based organizations-five cities, United States, 2007. MMWR Morb Mortal Wkly Rep. 2009;58:716-9.

14. Mimiaga MJ, Mayer KH, Reisner SL, Gonzalez A, Dumas B, Vanderwarker $\mathrm{R}$, et al. Asymptomatic gonorrhea and chlamydial infections detected by nucleic acid amplification tests among Boston area men who have sex with men. Sex Transm Dis. 2008;35:495-8.

15. Morris SR, Klausner JD, Buchbinder SP, Wheeler SL, Koblin B, Coates $T$, et al. Prevalence and incidence of pharyngeal gonorrhea in a longitudinal sample of men who have sex with men: the EXPLORE study. Clin Infect Dis. 2006;43:1284-9.

16. Patton ME, Kidd S, Llata E, Stenger M, Braxton J, Asbel L, et al. Extragenital gonorrhea and chlamydia testing and infection among men who have sex with men-STD Surveillance Network, United States, 2010-2012. Clin Infect Dis. 2014;58:1564-70.

17. Hui B, Fairley CK, Chen M, Grulich A, Hocking J, Prestage G, et al. Oral and anal sex are key to sustaining gonorrhoea at endemic levels in MSM populations: a mathematical model. Sex Transm Infect. 2015;91:365-9.

18. Annan NT, Sullivan AK, Nori A, Naydenova P, Alexander S, McKenna $A$, et al. Rectal chlamydia - A reservoir of undiagnosed infection in men who have sex with men. Sex Transm Infect. 2009;85:176-9.

19. Lutz AR. Screening for asymptomatic extragenital gonorrhea and chlamydia in men who have sex with men: significance, recommendations, and options for overcoming barriers to testing. LGBT Health. 2015;2:27-34.

20. Cunha CB, Friedman RK, de Boni RB, Gaydos C, Guimarães MR Siqueira $\mathrm{BH}$, et al. Chlamydia trachomatis, Neisseria gonorrhoeae and syphilis among men who have sex with men in Brazil. BMC Public Health. 2015;15:686.

21. Bernstein KT, Marcus JL, Nieri G, Philip SS, Klausner JD. Rectal gonorrhea and chlamydia reinfection is associated with increased risk of HIV seroconversion. J Acquir Immune Defic Syndr. 2010;53:537-43.

22. Centers for Disease Control and Prevention (CDC). Sexually Transmitted Diseases Treatment Guidelines, 2015. MMWR Morb Mortal Wkly Rep. 2015;64:1-137.

23. Cohen J, Lo YR, Caceres CF, Klausner JD, WHO guideline working group. WHO guidelines for HIV/STI prevention and care among MSM and transgender people: implications for policy and practice. Sex Transm Infect. 2013;89:536-8.

24. British Association of Sexual Health and HIV (BASHH). United Kingdom National Guideline for Gonorrhoea Testing 2012. [accessed 2017 Jul 8]. Available from: http://www.bashh.org/documents/4490.pdf.

25. Public Health Agency of Canada. Canadian Guidelines on Sexually Transmitted Infections, 2010. [accessed 2017 Jul 8]. Available from: http://publications.gc.ca/collections/collection_2011/aspc-phac/HP40-12010-eng.pdf.

26. Bourne C, Edwards B, Shaw M, Gowers A, Rodgers C, Ferson M. Sexually transmissible infection testing guidelines for men who have sex 
with men. Sex Health. 2008:5:189-91.

27. Blystad H, Klouman E. Recommendation for annual HIV and STI testing in MSM introduced in Norway. Euro Surveill. 2005;10:E050707.4.

28. Barbee LA. Preparing for an era of untreatable gonorrhea. Curr Opin Infect Dis. 2014;27:282-7.

29. Weinstock H, Workowski KA. Pharyngeal gonorrhea: an important reservoir of infection? Clin Infect Dis. 2009;49:1798-800.

30. van Liere GA, Hoebe CJ, Niekamp AM, Koedijk FD, Dukers-Muijrers NH. Standard symptom- and sexual history-based testing misses anorectal Chlamydia trachomatis and neisseria gonorrhoeae infections in swingers and men who have sex with men. Sex Transm Dis. 2013:4:285-9.

31. den Heijer CD, Hoebe CJ, van Liere GA, van Bergen JE, Cals JW, Stals FS, et al. A comprehensive overview of urogenital, anorectal and oropharyngeal Neisseria gonorrhoeae testing and diagnoses among different STI care providers: a cross-sectional study. BMC Infect Dis. 2017;17:290

32. Aberg JA, Kaplan JE, Libman H, Emmanuel P, Anderson JR, Stone VE, et al. Primary Care Guidelines for the Management of Persons Infected With HIV: 2013 Update by the HIV Medicine Association of the Infectious Diseases Society of America. Clin Infect Dis. 2009;49:651-81. 